\title{
Reforecast of the November 1994 flood in Piedmont using ERA5 and COSMO model: an operational point of view
}

\author{
Valeria Garbero $^{1}$ (D) Massimo Milelli $^{1}$
}

Received: 31 March 2020 / Accepted: 2 December 2020/ Published online: 15 January 2021

(C) The Author(s) 2021

\begin{abstract}
The scope of this work is to assess the progresses made in the warning alert system of Piedmont since the 1994 flood. We used the COSMO model at high horizontal resolution forced by ERA5 re-forecast to simulate the November 1994 event, performing also a simple sensitivity test regarding the parameterization of convection. We compared the results with the original forecast and with the available observations, in order to understand how the emission of the alert would have been affected using the current operational system.
\end{abstract}

Keywords Alert system $\cdot$ Flood $\cdot$ November $1994 \cdot$ Piedmont $\cdot$ Special issue $\cdot$ BAST

\section{Introduction}

In the first days of November 1994, Piedmont was hit by a disastrous flood. The persistence of a wide depression over western Europe caused heavy rains on a large part of Piedmont region between 4 and 7 November 1994. The strong confluence of surface currents from southeast and upper-level flow from south and southwest, as explained in the Arpa Piemonte Report (Arpa Piemonte 1998), caused exceptional rainfall peaks over the mountain basins of Tanaro and Bormida (Maritime Alps) and the north-western sector of the region. Rainfall led to large floods along the rivers and numerous rock block slides that were responsible for considerable damages and numerous victims.

From a meteorological point of view, the event has been studied extensively during the MAP Programme (Binder et al. 1996) and resulted from a complex interaction between

Valeria Garbero

valeria.garbero@arpa.piemonte.it

Massimo Milelli

massimo.milelli@arpa.piemonte.it

1 Arpa Piemonte, Turin, Italy 
synoptic and mesoscale flows (Buzzi and Tartaglione 1995; Buzzi et al. 1995; Binder and Rossa 1995), in agreement with other diagnostic studies (Doswell et al. 1998). Piedmont region lies in the north-western part of the Mediterranean basin, where complex orography is present: high mountains, narrow valleys, plains and coastline are sometimes very close, providing a common denominator to this kind of atmospheric flow which brings floods or flash floods in the area (Rotunno and Ferretti 2001; Milelli et al. 2006).

Several numerical simulations have been conducted (also idealized) to better characterize the role of orography and moist processes, concluding that an increase of model resolution is necessary but probably requires a simultaneous increase in the complexity of the microphysical representation and of the convective parameterization schemes (Buzzi et al. 1998). In general, real simulations with limited area models (LAMs) were able to predict in reasonable way the precipitation pattern (Ferretti et al. 2000), at least considering eye-ball verification. Forecast with a LAM in ensemble mode was also performed by Marsigli et al. (2001). It is also noticeable that the largest part of the humidity was provided mainly by advection from the distant part of the Mediterranean Sea or from the Atlantic Ocean rather than from the Ligurian Gulf (Cassardo et al. 2002).

If we enlarge the perspective and include also hydrological aspects, it has to be mentioned the "USA-Italy Research Workshop on the Hydrometeorology, Impacts, and Management of Extreme Floods", where a selected group of specialists discussed and exchanged experiences in relation to catastrophic flood events. The research workshop was held at the Water Research and Documentation Centre of the University for Foreigners, La Colombella, Perugia, Italy, between 13 and 17 November 1995. The contributions covered different aspects of the problem. In part I of the workshop (learning from the experience of the recent extreme floods in the USA and Europe), Marchi et al. (1995) provided an historical classification from a discharge perspective, while Brath (1995) introduced the QPF determination topic, crucial for hydrology purposes. In part II (hydrometeorology of extreme floods), La Barbera and Lanza (1995) observed how remote sensing can help in the nowcasting activity, while Castelli (1995) introduced the uncertainty aspect, related to space-time resolution of short-term precipitation predictions, and states that the propagation of uncertainty in a meteohydrological chain acquires more and more importance. Since the most relevant deficiency turned out to be the wrong localization of the highest precipitation clusters (Ferraris et al. 2002), the scientific community started dealing with probabilistic forecast (Bartholmes and Todini 2005) in combination with some technique to be used as a bridge from the meteorological to the hydrological scales, such as a multifractal disaggregation scheme of the large-scale predicted rainfall (Ferraris et al. 2002).

In general, the available literature about the 1994 flood is huge, ranging from the analysis of the event, to the meteorological forecast, to the hydrological forecast and to the uncertainty propagation in the whole chain. So, we will focus on a different aspect and deal with the event from an operational point of view. We will describe the past and current warning system in Arpa Piemonte, which was created to inform the population of possible risks related to adverse weather phenomena. We will show how, nowadays, the forecast of the event provided by the current operational COSMO model would affect the issue of a weather alert, and we will highlight the progresses made in the operational chain of the warning system.

The paper is organized as follows. We briefly describe the synoptic of the event in Sect. 2 and the warning system of Arpa Piemonte in Sect. 3. Then, we introduce the COSMO model and the simulation setup in Sect. 4. Results are shown in Sect. 5, and finally, we summarize the conclusion in Sect. 6. 


\section{Synoptic situation}

During 2 and 3 November 1994, the meteorological situation over Europe was characterized by the presence of a deep high-level trough with a minimum positioned over Iceland deepening towards the coasts of north Africa (Fig. 1). On 4 November, the trough slowly moved towards east, while an anticyclone over east Europe, extending from the central Mediterranean to Scandinavia, remained almost stationary. This implied the intensification of the geopotential gradient and of a southerly flow on the east side of the trough that collected a large amount of humidity passing over the Mediterranean Sea. This meridionally elongated upper-level trough was embedded in an incoming Rossby wave packet that originated in the Pacific and whose propagation modulated the transport of the large moisture quantity from the central Atlantic towards the Mediterranean, with a formation of an atmospheric river (AR) over the central Mediterranean Sea (Grazzini et al. 2020). The complex orography of the Alps and Apennines played a crucial role. On that day, the high-level currents flew from south-west, while in the lower atmosphere there was a convergence over the southern Piedmont region, due to an easterly flow over the Po valley and south-easterly winds from the Genoa Gulf across Apennines. Convection contributed to the intensification of the rainfall over this area mainly. The following day (5 November; see Fig. 2), high-level southern currents continued to flow and intensified, interacting with a prefrontal low-level jet. The mass convergence of these two branches in the western Po valley triggered high vertical velocities on the upwind side of the orography, generating intense and persistent orographic precipitation over north-western sector and Maritime Alps.

From 6 November, the trough gradually started moving eastwards (Fig. 2) due to the gradual attenuation of the high-pressure structure over the Balkans. The precipitation, however still substantial, extended to the northeast Italian regions, only marginally affected by light rain in the previous days. Finally, on 7 November, the trough moved towards the Balkans, causing only residual rainfall over northern Italy.

\section{The operational warning system in Piedmont}

In 1994, the Natural Risks Operational Room of Piedmont Region was recently established. The law no. 225, 24 February 1992, which established the National Civil Protection Service,
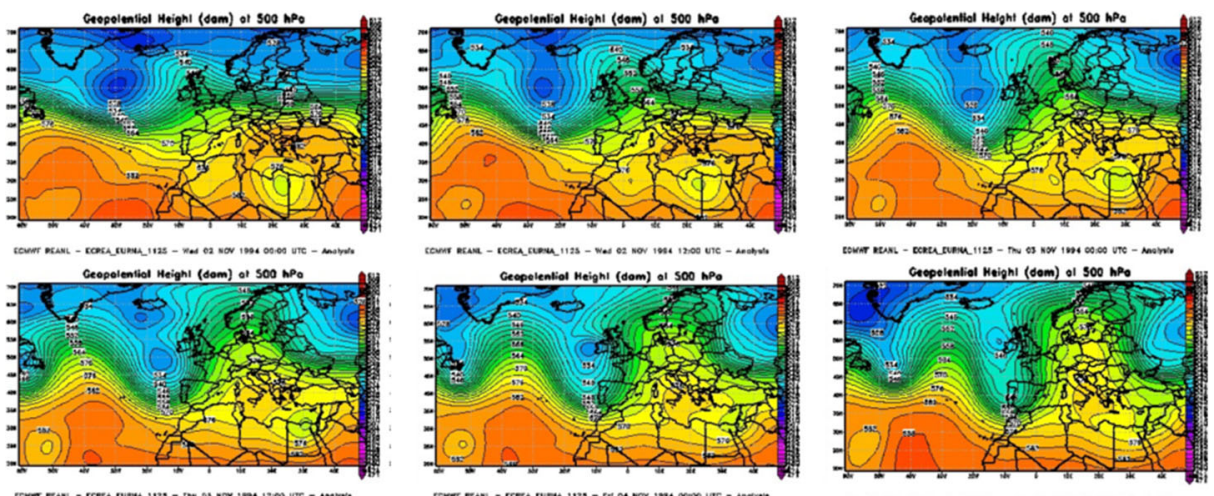

Fig. 1 ERA5 charts of $500 \mathrm{hPa}$ geopotential from 2 November 1994 00UTC to 4 November 1994 012UTC 


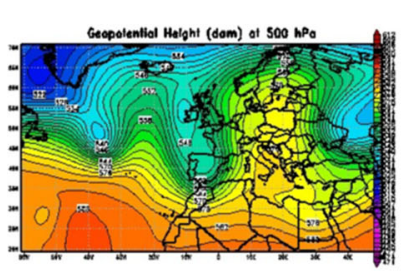

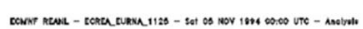

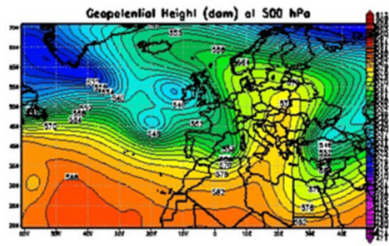

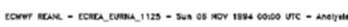

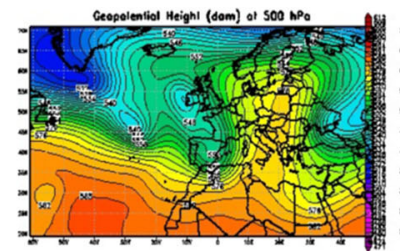

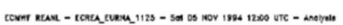
Geopolentiol Heighl (dam) of $500 \mathrm{hPa}$
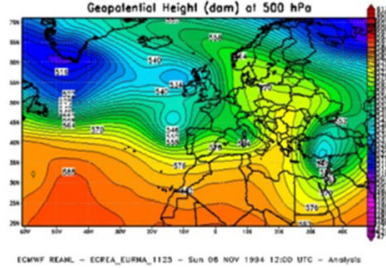
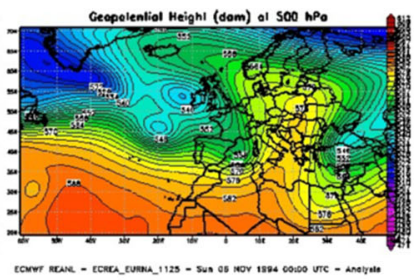

Geopotentiol Height (dom) ot $500 \mathrm{hPo}$

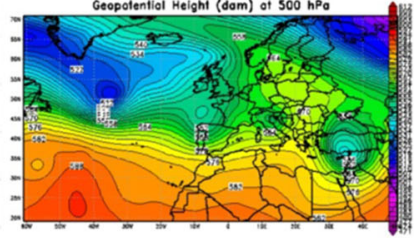

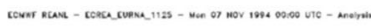

Fig. 2 ERA5 charts of $500 \mathrm{hPa}$ geopotential from 5 November 1994 00UTC to 7 November 1994 00UTC

provided the implementation of regional forecasting and prevention programs and assigned to the Natural Risk Operational Room the management of monitoring networks and forecasting models. The observational network in Piedmont consisted of 91 ground stations, and there was no meteorological radar. Two agreements, signed with the Italian Air Force Meteorological Service and ENEL Ricerche, provided forecasting meteorological products from ECMWF with a grid spacing of about $100 \mathrm{~km}$ and 31 vertical levels and from the limited-area model MEPHISTO at about 15-km resolution. The LAM MEPHISTO supplied quantitative precipitation forecasts in $12 \mathrm{~h}$, for the following $72 \mathrm{~h}$, over 3 different sectors of Piedmont, Cozie and Maritime Alps, Pennine and Lepontine Alps and Western Plain. A bulletin was emitted every day by the Natural Risks Operational Room and transmitted to the competent authorities including the National Civil Protection. The 1994 tragedy pointed out that operational warning system as structured at that time did not work, and it was the starting point for the reorganization of the whole regional alert system, the improvement and extension of the observational network, and the definition of the technical and communication procedures to inform authorities and population about critical issues. The Natural Risks Operational Room, now Regional Functional Centre, became the focal point of the system.

Nowadays, the number of ground stations is more than 400, uniformly distributed over the territory; there are two meteorological radars, four radiometers and a radiosonde. In addition, the satellite products improved considerably the monitoring phase. The regional alert system is defined by a forecasting phase and a monitoring and surveillance phase, both implemented by the Regional Functional Centre. Arpa Piemonte, every day at 13:00 local time, issues a daily weather bulletin reporting relevant meteorological phenomena and a daily alert bulletin containing a forecast of weather phenomena and expected ground effects for hydrogeological and hydraulic risks. The warning for meteorological and hydraulic risk is carried out on predefined areas of the regional territory, consisting of aggregations of municipal territorial areas and characterized by homogeneous meteorological and/or hydrological response at the onset of the risk. Hydrographic, meteorological and orographic criteria are used for the definition of the alert areas, considering the administrative limits. Piedmont region is divided into 11 alert areas, as shown in Fig. 3, for each of which a threshold is defined in relation to the probability of occurrence and to the duration of the precipitation. 


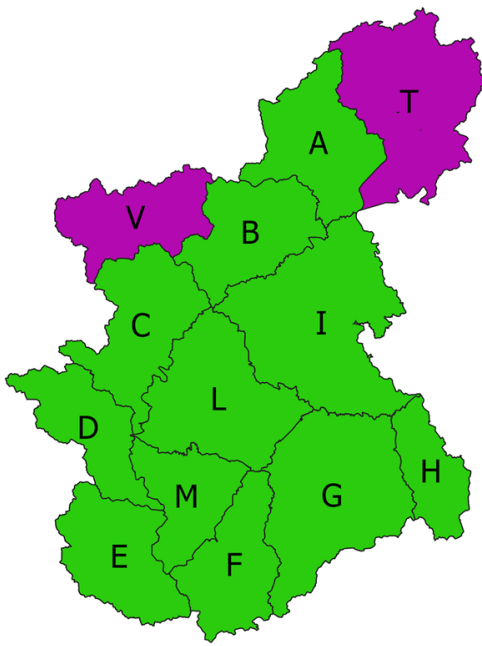

Warnig areas

$\square$ A : Toce

$\square$ B : Dora Baltea - Sesia

$\square$ C : Orco - Bassa Dora Riparia - Sangone

$\square$ D : Alta Dora Riparia - Po

$\square$ E : Varaita - Stura

$\square \mathrm{F}$ : Alto Tanaro

$\square$ G : Belbo - Bormida

$\square$ H : Scrivia

$\square$ I : Pianura settentrionale

$\square$ L : Pianura Torinese - Colline

$\square \mathrm{M}$ : Pianura Cuneese

$\square \mathrm{T}$ : Ticino

$\square$ V : Dora Baltea

Fig. 3 Alert areas in Piedmont (green colour)

From the meteorological point of view, which is what we are investigating in this work, both bulletins are fed by the precipitation forecast on each alert area. Every day, the weather forecaster consults the outputs of global and high-resolution models and, also based on his experience, provides, for each alert area, average and maximum precipitation over $6 \mathrm{~h}$ for the afternoon (+ $12 \mathrm{~h}$ ) and the 2 following days $(+12 /+36 \mathrm{~h}$ and $+36 \mathrm{~h} /+60 \mathrm{~h}$, respectively). Average precipitation is classified in 5 levels related to the intensity (absent, weak, moderate, heavy and very heavy), while maximum precipitation is classified in shower, thunderstorm, heavy thunderstorm and strong and persistent thunderstorms (Fig. 4). The average values are used to evaluate the hydrogeological and hydraulic risks, while the maxima are used to evaluate the thunderstorm risk (hydrogeological for thunderstorms). The daily weather bulletin is compiled by evaluating the expected precipitation according to the described criteria and aims to inform the Civil Protection Authorities in relation to the forecast of significant meteorological phenomena.
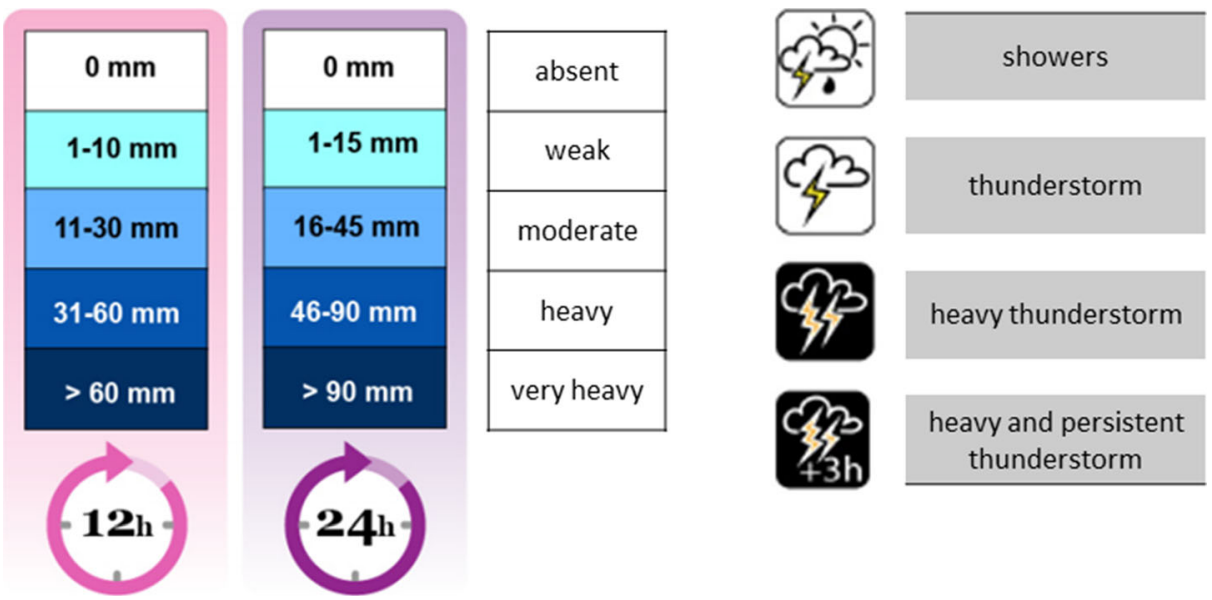

Fig. 4 Classes of average precipitation in $12 \mathrm{~h}$ and $24 \mathrm{~h}$ (left) and icons for the classification of thunderstorms (right) in the meteorological bulletin 
The alert bulletin contains the forecast of critical issues for the afternoon $(+12 \mathrm{~h})$ and the following day $(+12 /+36 \mathrm{~h})$ on a scale of alert areas for the following phenomena: hydraulic, geohydrological, geohydrological for thunderstorms, snowfalls and avalanches. It is based on the expected risk scenarios and effects and damages and is compiled by comparing the expected precipitation with the thresholds identified for each area. The alert is classified in 4 increasing levels, characterized by a green, yellow, orange and red colour, which correspond to different event scenarios and potential effects and damage on the territory.

The bulletins are transmitted to Civil Protection and all competent authorities. Their behaviour is then specified by a set of shared procedures according to the scenario of risk established by the colour of the alert.

\section{COSMO model and simulation setup}

The COSMO model is a non-hydrostatic limited-area atmospheric model developed within the COSMO Consortium for both operational numerical weather prediction (NWP) and various scientific applications on the meso- $\beta$ and meso- $\gamma$ scale (for a more comprehensive description, see the official documentation (Doms and Baldauf 2013, 2018, Doms et al. 2013). Arpa Piemonte is a member of the Consortium since 2000. The model is based on non-hydrostatic, fully compressible equations describing compressible flow in a moist atmosphere and uses generalized terrain-following height coordinates with rotated geographical coordinates. The model equations are solved on an ARAKAWA C-grid with second-order finite difference method, while time integration uses a Runge-Kutta scheme of 3rd stage (Wicker and Skamarock 2002). Data at the lateral boundaries are prescribed using a Davies-type one-way nesting (Davies 1976). Subgrid-scale turbulence is parameterized by a prognostic equation for the turbulence kinetic energy, including effects from subgrid-scale condensation and evaporation (Mellor and Yamada 1982). The surface layer parameterization is based on turbulent kinetic energy and includes a laminar-turbulent roughness layer. The formation of precipitation is described by a bulk microphysics parameterization including water vapour, cloud water and ice, rain and snow with a fully prognostic treatment of precipitation. There is an option for a new bulk scheme including graupel. Condensation and evaporation are parameterized by saturation adjustment, while depositional growth/sublimation of cloud ice is calculated using an explicit non-equilibrium growth equation (Reinhardt and Seifert 2006). Subgrid-scale cloudiness used for radiation calculations is parameterized by an empirical function depending on relative humidity, ice content and height. Radiation is calculated using a two-stream scheme for short- and long-wave fluxes including a full cloud-radiation feedback (Ritter and Geleyn 1992). A multilayer soil model (TERRA, see Doms et al. 2013) is applied. Concerning moist convection, it is parameterized using a mass-flux scheme with an equilibrium closure based on moisture convergence following Tiedtke (1989), but there is an option for the current IFS Tiedtke-Bechtold convection scheme both for deep and shallow convection (Bechtold et al. 2001). By employing the kilometre-scale resolution, it is expected that deep moist convection develops on the model grid, whereas shallow cumulus convection is far from being resolved (Khain et al. 2021). An option has been developed in COSMO to choose Tiedtke or Bechtold scheme for parameterizing the shallow convection.

The COSMO model has been adopted by the Italian National Civil Protection Department as a reference, together with the ECMWF global model, for the emission of national weather alerts (see DPCM 2004). In the national context, the Meteorological Service of the Military Air 
Force, the IdroMeteoClima Service of Arpae Emilia-Romagna and Arpa Piemonte signed an agreement, called Lami, which states the collaboration for development and operational management of the modelling chains. The operational modelling chain includes two main configurations, one with a 5-km grid spacing over the Mediterranean area (COSMO-5M) up to $+72 \mathrm{~h}$ and one with a $2.2-\mathrm{km}$ grid spacing over Italy (COSMO-2I) up to $+48 \mathrm{~h}$ (http://www. cosmo-model.org/content/tasks/operational/arpae-simc/default.htm). Both simulations are initialized twice a day, at 00UTC and 12UTC. COSMO-5M uses IFS boundary conditions, and the initial conditions are provided by the LETKF method (Bonavita et al. 2010), while COSMO-2I is nested directly into COSMO-5M, but the initial conditions are provided by a data assimilation cycle based on the COSMO Kenda system (Schraff et al. 2016).

In this work, we adopted the operational configuration except for the fact that the domain over Italy was partially reduced, and no data assimilation was applied. The initial and boundary conditions for COSMO-5M were provided by a new set of experiments performed by ECMWF and dedicated to this major flood (Ferrero and Balsamo 2020). COSMO-5 M runs, forced by the IFS HRES reforecast at grid spacing of $9 \mathrm{~km}$, from 4th November 1994 00UTC up to $+48 \mathrm{~h}$, and COSMO-2I run nested into COSMO-5 M. The ECMWF's new experiments were driven by the new climate reanalysis dataset ERA5, covering the period 1950 to present and being developed through the Copernicus Climate Change Service (C3S). ERA5 HRES data were produced using 4D-Var data assimilation in cycle "cy41r2" of ECMWF's IFS, with 137 vertical levels and 31-km horizontal resolution (Hersbach et al. 2020).

Although the event was mainly stratiform and orography-driven, intense convection activity affected the southern part of Piedmont, especially the 4th November. So, a simple sensitivity test on the parameterization of convection has been performed in COSMO-2I runs. Since at 2-km grid spacing, the deep moist convection could be explicitly resolved (see for instance Buzzi et al. 2014), we tested the 2 available parameterizations for the shallow convection: Tiedtke (TIE) and Bechtold scheme (BEC). Finally, we excluded any parameterization, keeping the hypothesis of fully explicit convection (NCV). The 3-hourly precipitation provided by the different model configurations was compared with the observations, and the 6hourly precipitation was directly used to feed the daily weather bulletin and the daily alert bulletin.

\section{Results}

The different studied model configurations have been evaluated qualitatively by visually comparing the forecast maps of precipitation with the spatial rainfall distribution estimated, using the Kriging interpolation technique, from the measurements provided by the meteorological network available at that time (Fig. 5). Also, some statistical index has been calculated to quantify the model performance by comparing 3-h precipitation measured at each station with the same values extracted from the simulated field at each corresponding station.

Figures 6 and 7 show the comparison of the observed average daily precipitation with the one provided by the model in the 3 tested configurations for 4 and 5 November, +24 h (D0) and $+48 \mathrm{~h}$ (D1), respectively. The pattern of precipitation looks coherent among the different forecast and the observation, especially for 4 November, since the most affected areas are well predicted. A slight overestimation can be seen over A and B areas, less pronounced in the BEC run. The largest amount of rain over the Apennines is predicted too east, and the peak is 
Fig. 5 Rain gauge network of Piedmont Region in 1994

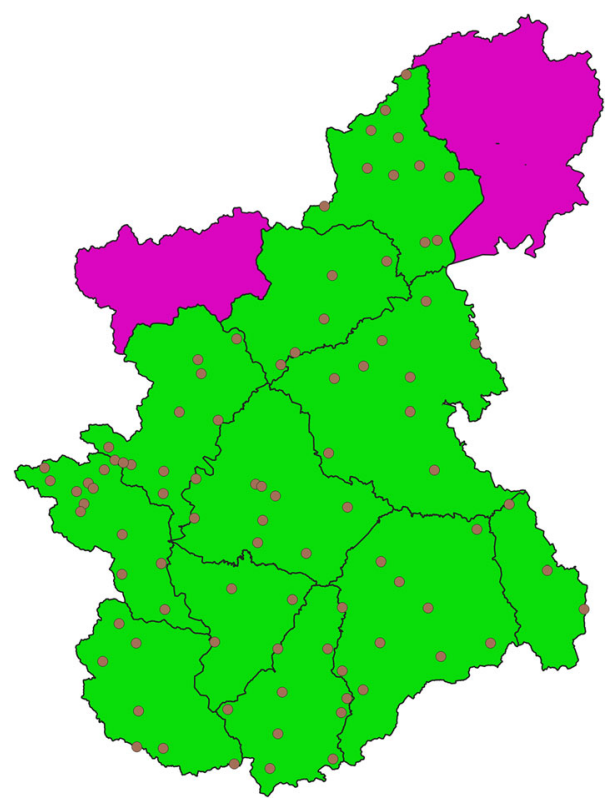

underestimated, but it is still in the $\mathrm{G}$ area. The amount of precipitation expected during 5 November is overestimated over the Ligurian Alps, although the peak in Area F is correctly positioned, and over north-western areas. The tested configurations do not exhibit significant differences.

In order to have also a quantitative estimation of the model performance in its different configurations, we compared the 3 -h precipitation measured by the stations with the values extracted through bilinear method from the simulated field at the station point. In Fig. 8, we show the Taylor's diagram (Taylor 2001) for the different configurations for 4 (D0) and 5 November (D1). As the centred RMS error indicates, the performance of the models is rather good for D0 ( $+24 \mathrm{~h})$ but deteriorates for D1 with increasing lead time $(+48 \mathrm{~h})$. The minimal differences in the model performance in the 3 different tested configurations do not seem to be statistically significant. Even if we focus on the southern reliefs in the afternoon of 4 November, where the convective phenomena had occurred, the different approach in dealing with shallow convection has a minor impact on the results, as shown in Fig. 8 (bottom line).

In order to better explain the operational approach, based on classes of precipitation, we focus on the average and maximum precipitation on each alert area, both observed and simulated. In Figs. 9 and 10, we show the average and maximum precipitation in $12 \mathrm{~h}$
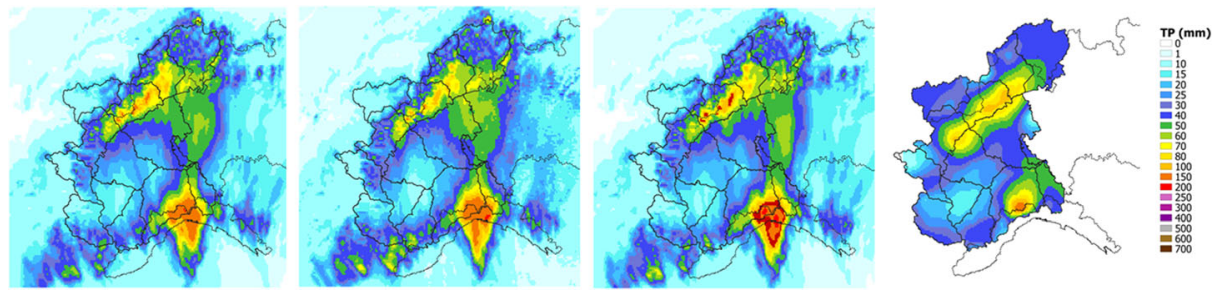

Fig. 6 24-hour precipitation for 4 November 1994: COSMO-2I $+24 \mathrm{~h}$ forecast TIE, COSMO-2I $+24 \mathrm{~h}$ forecast $\mathrm{BEC}, \mathrm{COSMO}-2 \mathrm{I}+24 \mathrm{~h}$ forecast NCV, observed field (Kriging interpolation) 

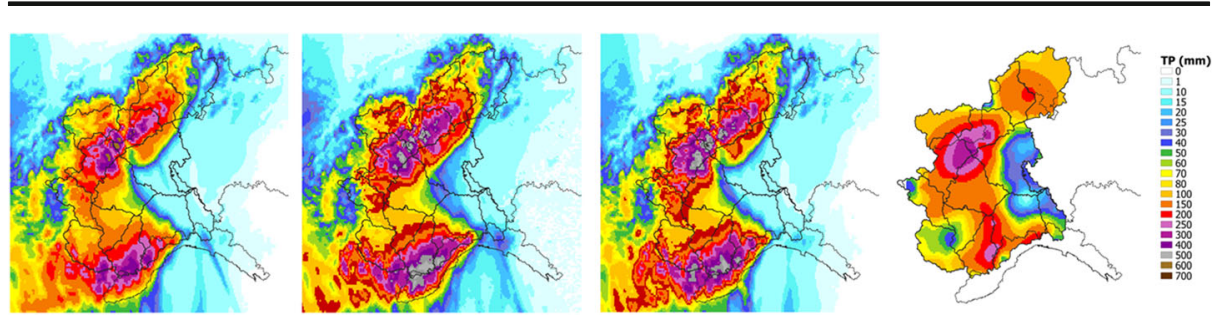

Fig. 7 24-hour precipitation for 5 November 1994: COSMO-2I + $24 \mathrm{~h}$ forecast TIE, COSMO-2I + $24 \mathrm{~h}$ forecast BEC, COSMO-2I $+24 \mathrm{~h}$ forecast NCV, observed field (Kriging interpolation)

concerning the afternoon of 4 November and in 24 h concerning 5 November 1994 for each alert area for the different tested simulations. The good behaviour of the models is confirmed for 4 November (D0), even if there is a slight overestimation of total precipitation in the Pennine and Lepontine Alps (area A) and a slight underestimation on the Apennines areas (G and $\mathrm{H}$ ). The NCV and TIE patterns seem more similar to observation than BEC, even if the differences are not significant.

The forecast for 5 November shows a worst behaviour as the amount of precipitation over Alpine sector is overestimated, both in the average and in the maximum, and underestimated over the Apennine sector. However, despite the quantitative precipitation forecast is overestimated, its pattern is rather correct since the more affected areas are well captured. The BEC configuration appears to be the closest to the observations as TIE and NCV underestimate the amount of rain over the central plains.
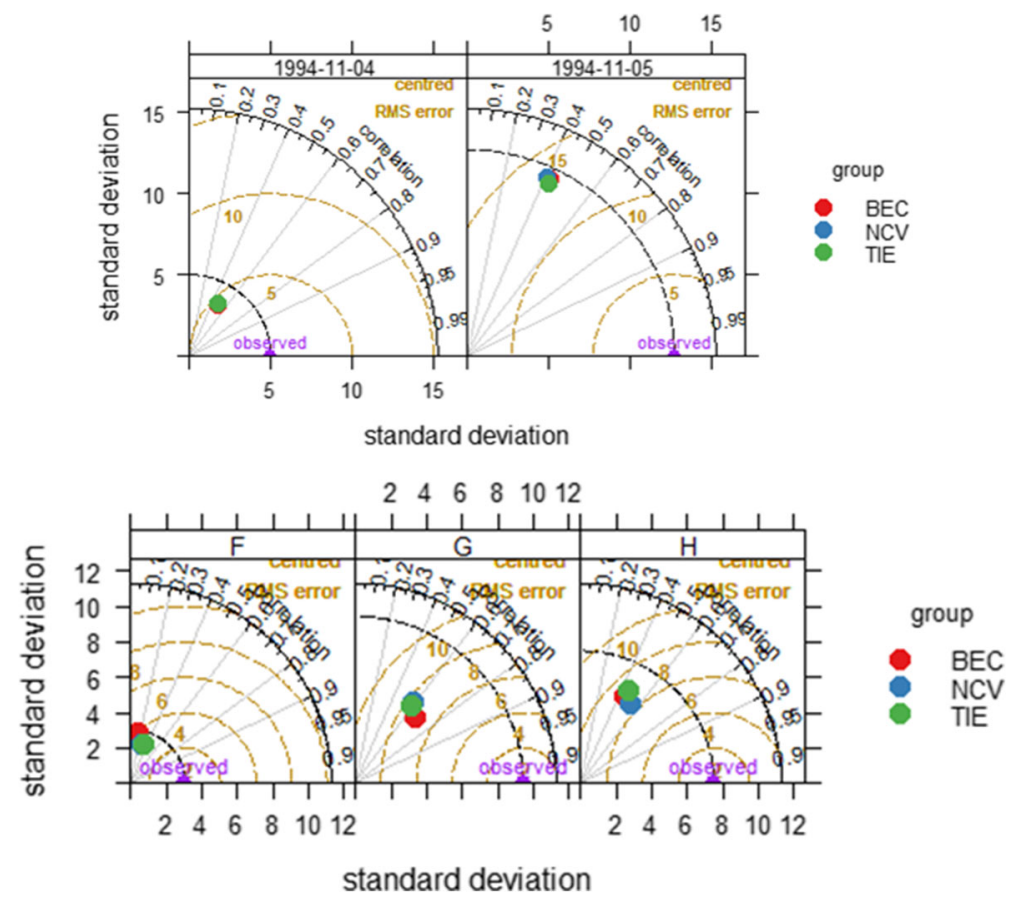

Fig. 8 Top: Taylor's diagram for 4 (top left) and 5 (top right) November for the different tested configurations. Bottom: focus on the afternoon of 4 November over the southern alert areas $(F, G$ and $H)$ 

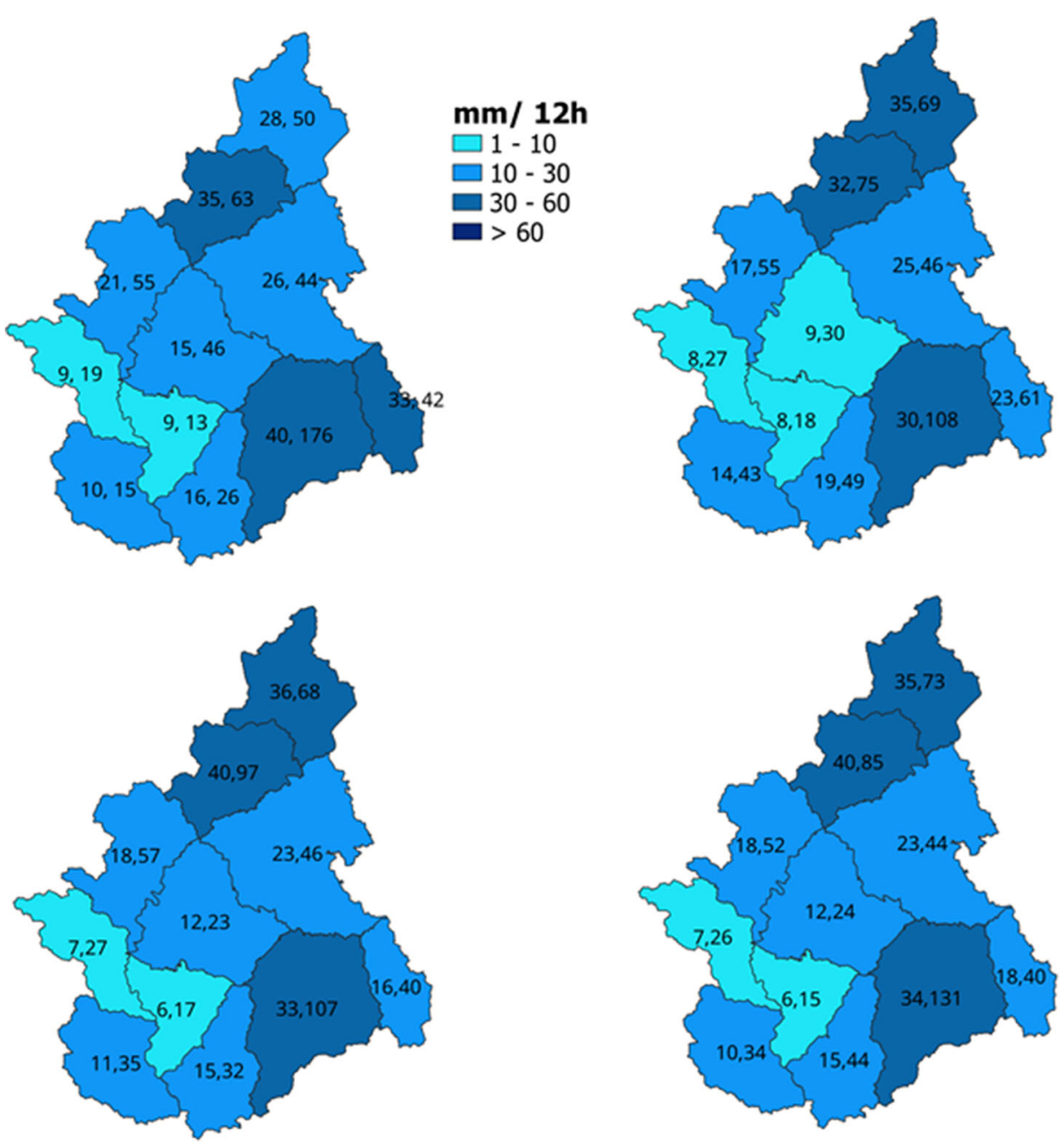

Fig. 9 Comparison of mean (left number) and maximum (right number) 12-hour precipitation estimated over each alert area for the afternoon of 4 November 1994: observations (top left), BEC simulation (top right), TIE simulation (bottom left) and NCV simulation (bottom right)

For further considerations, we use the BEC results, bearing in mind that using the other configurations would not have determined significant differences. Indeed, from the perspective of a forecaster in the operational room, the alert based on thresholds over areas allows to take into account a certain degree of uncertainty. The 6-hourly average and maximum precipitations on each area foreseen by the selected COSMO model configuration have been used to issue the weather and alert bulletin that appear in Fig. 11. The model output has been used directly and has not been modified by the meteorologist, as happens in the operational forecasting. In the meteorological bulletin (on the left side), the figure on top-left refers to the forecast for the afternoon of 4 November $(12 \mathrm{~h}$ ), and the dark blue colour corresponds to a $60-\mathrm{mm} / 12-\mathrm{h}$ threshold, while the figure on top-right refers to the forecast for 5 November ( $24 \mathrm{~h}$ ), and the dark blue colour corresponds to a $90-\mathrm{mm} / 24$-h threshold. The figure on bottom-left refers to 6 November, and it is empty because the boundary conditions for that day were not available. 

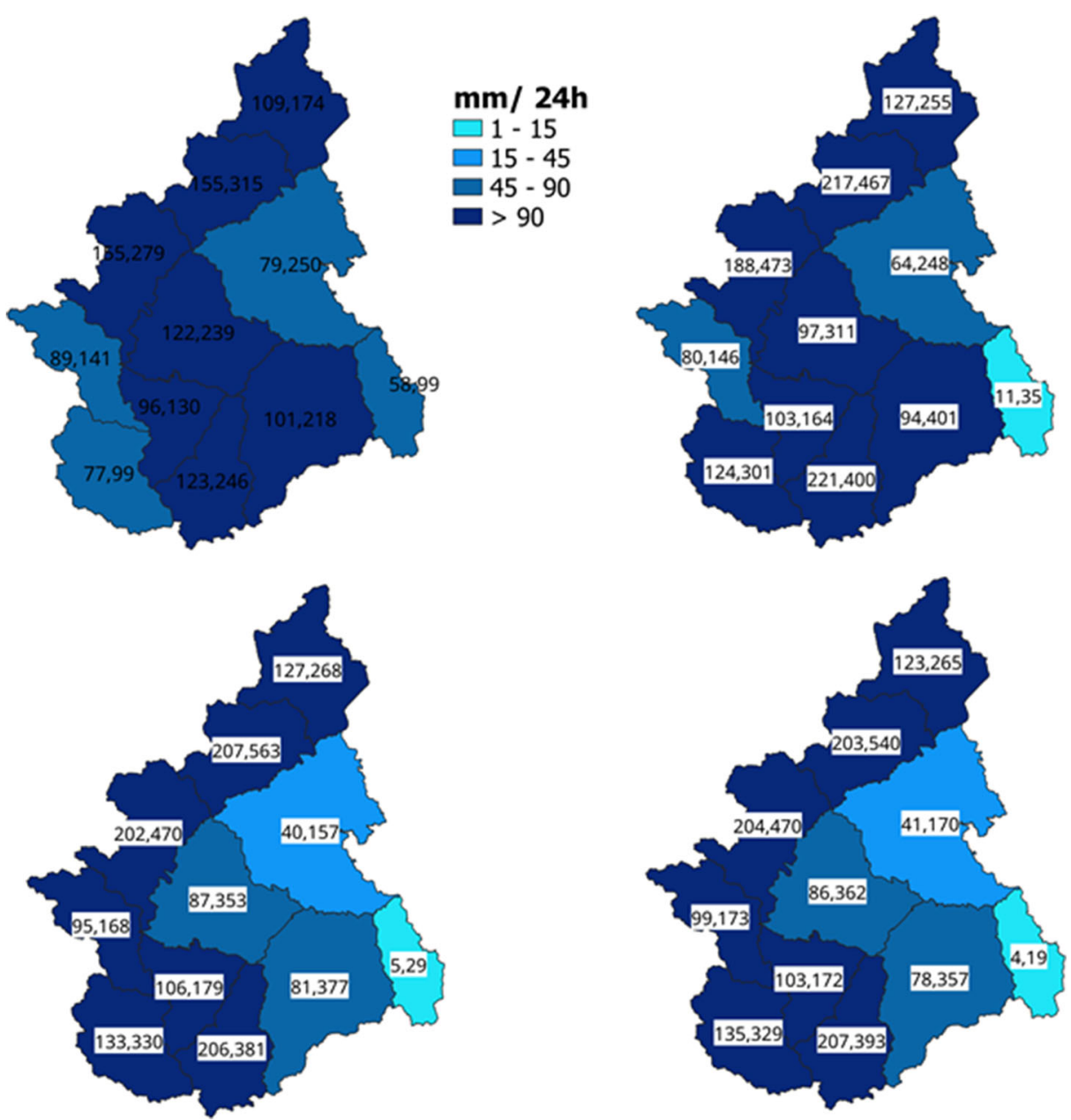

Fig. 10 Comparison of mean (left number) and maximum (right number) 12-hour precipitation estimated over each alert area for the afternoon of 5 November 1994: observations (top left), BEC simulation (top right), TIE simulation (bottom left) and NCV simulation (bottom right)

Concerning the afternoon of 4 November, high precipitation is expected in alert areas A, B and $\mathrm{G}$ and heavy thunderstorms (triggered by the maxima in Fig. 10) in $\mathrm{G}$ and $\mathrm{H}$; due to the described weather phenomena, a yellow alert is issued for the Apennine area ( $G$ and $H)$ in the alert bulletin. For 5 November, very high precipitation is expected on almost the whole region, except for I, H and D areas, while heavy thunderstorms could still involve Maritime and Ligurian Alps and Apennines (mean and maxima in Fig. 11). A red alert is issued for the northwestern (B and $\mathrm{C}$ areas) and southwestern (E and F) sectors, and an orange alert affects all the plains and western Apennines. For the names of the areas, please refer to Fig. 4. It has to be remembered that these considerations come from a purely meteorological input, and then the alert only derives from the expected amount of rain and not from hydrological or landslide models. Nevertheless, it is reasonable to infer that the hydrological model, which also works using a threshold system, would have pointed out the risk of the Tanaro river (which starts in the F area) to flood the Asti and Alessandria zones (in $\mathrm{G}$ area). The red alert for hydraulic risk 

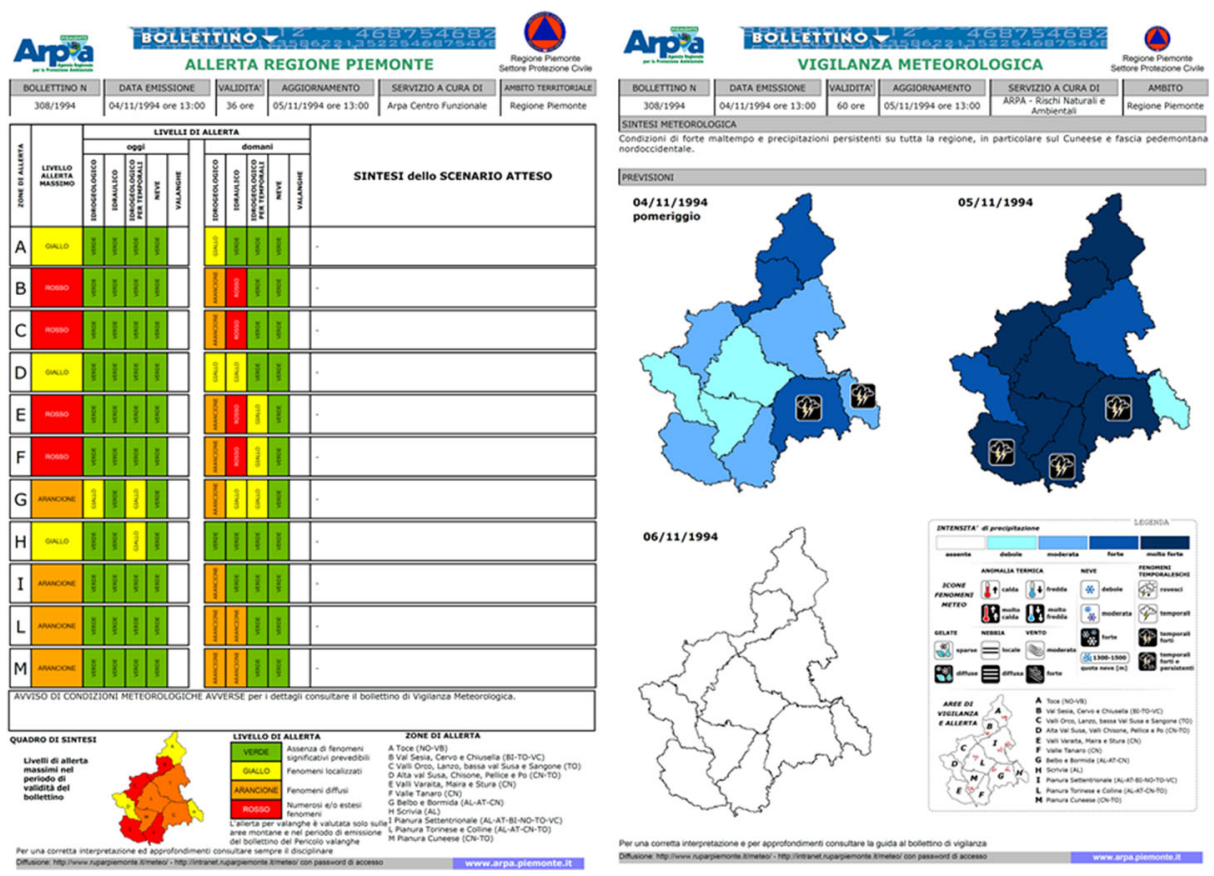

Fig. 11 Weather bulletins of the 1994 event reconstructed with the COSMO-2I reforecast. The meteorological (only informative) bulletin on the left and the alert bulletin on the right

corresponds to flooding of major rivers, flooding of areas even far from the river, widespread erosion of banks, rupture of embankments, and bridge overhangs and constitutes a serious danger to the safety of the people with possible victims.

The tools available in 1994 were, thanks to the meteorological support of ENEL Ricerche, the ECMWF global model and the limited-area model MEPHISTO. The ECMWF synoptic charts indicated already on 2 November western Alps and southern Piedmont as the most probably affected areas, and this was confirmed by the 3 November forecast (Arpa Piemonte 1998). Figure 12 shows the 24-h precipitation provided by the IFS forecast issued on 5 November 1994 at 00UTC, when the cycle "cy11r7" (horizontal resolution equivalent to 60/ $80 \mathrm{~km}$ approximately) was in operation. The pattern indicates intense precipitation over western and southwestern Alps, and those values were unusual for a global model with such a coarse resolution. Unfortunately, we do not have the maps provided by the MEPHISTO model, but only some information mentioned in the Arpa Piemonte Report (Arpa Piemonte 1998) on the expected amount of rain: exceptional rainfall conditions (over $50 \mathrm{~mm} / 12 \mathrm{~h}$ ) were expected over Maritime and Cozie Alps between 5 November 12UTC and 6 November 12UTC. If we compare the current model with those available at that time, it is impressive how much the resolution has improved, which has a major impact on the forecast of the event, both in terms of precipitation pattern and expected amount of rain.

Based on the numerical forecasts provided by the ENEL Ricerche, the Natural Risks Operational Room of Piedmont Region issued a bulletin on 3 November to advise population that very high precipitation was expected on the Alps with exceptional values in the centralsouthern sector between 4 and 6 November. In the afternoon of the same day, an extraordinary weather bulletin was sent to local authorities, warning against possible hydrogeological 


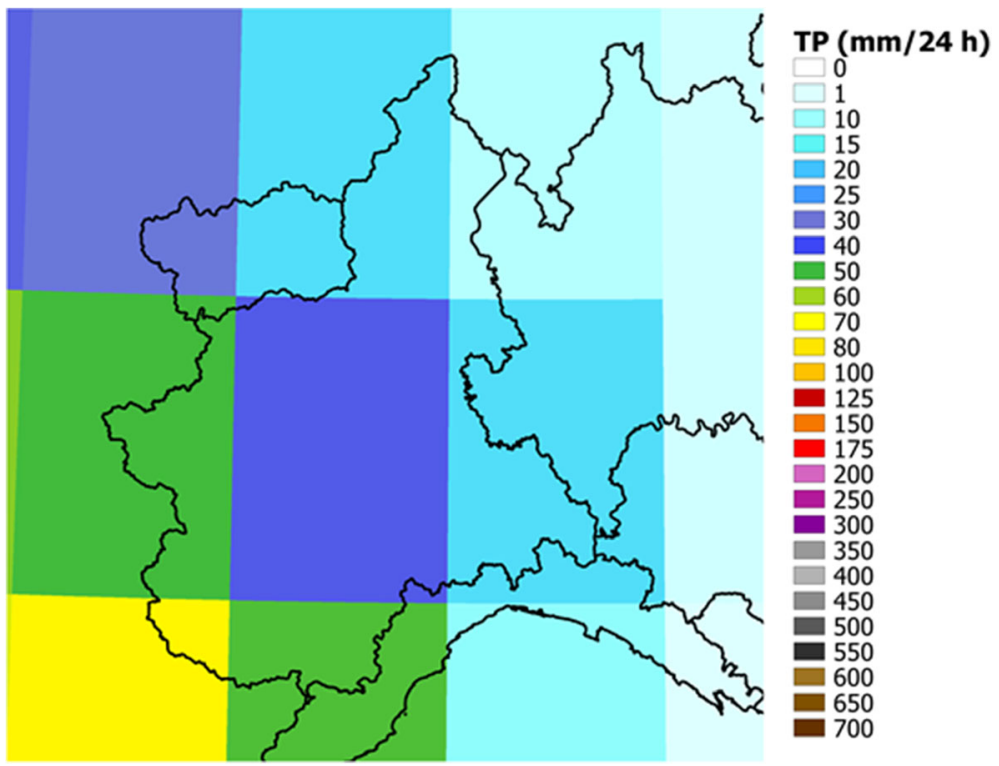

Fig. 12 24-hour precipitation for 5 November 1994, + 24 h forecast of the ECMWF deterministic model issued on 5 November 1994 at $00 \mathrm{UTC}$

instability over western Apennines (F and G areas) and Alpine sector (E, D, C areas), which may require a state of alert of the bodies responsible for civil protection functions. Due to the high number of victims, there was a great debate about what was to blame. Discussions in court proceedings have demonstrated that the forecast was substantially correct, since the most affected areas were properly predicted, and the exceptionality of the event was grasped. On the contrary, there were shortcomings in the alerting process, particularly regarding communication systems, and it was evident the difficulty of translating a quantitative numerical forecast into a warning text and into the activation of the consequent and standardized safeguard actions to protect the population. In addition, due to the lack of adequate instrumentation and a well-calibrated hydrological model, an estimate of the evolution of the event in hydrographic terms was lacking. Therefore, this dramatic event was an impulse for the reorganization of a more efficient regional alert system.

\section{Conclusions}

In November 1994, a tremendous flood-hit Piedmont and caused enormous damage and numerous deaths, despite the predicted exceptionality of the event. It was evident the lack of communication and the difficulty of translating a quantitative forecast into a warning text and in standardized actions to safeguard the population. This tragedy was somehow an impulse to reorganize the alert system and to create a more extended and comprehensive network of observations. In this work, we adopted an operational point of view to analyse the event, showing how the current warning system works compared with the one of the time and simulating the event with the actual available models.

IFS model reforecast, driven by ERA5, provided the boundary conditions for COSMO model forecast simulations from 4 to 5 November, using different configurations for the 
shallow convection parameterization. Two different schemes and the full explicit convection were compared and showed not significant differences. The precipitation pattern was correctly reproduced by the models, which captured the areas most affected by the rain, despite an overestimation over the Alpine sectors. It must be considered that no data assimilation has been carried out and that the run on 5 November at 00UTC could have provided even more satisfactory results. The data assimilation process and the formulation of the initial conditions are crucial aspects of NWP and some of the key factors in the meteorological modelling progress. The results indeed demonstrate that the COSMO model has been able to forecast the flood more correctly than the past, due to higher resolution and improved physical schemes, although we must bear in mind that numerical weather forecasting, even at convectionresolving resolutions, is still subject to large errors, due to many factors, including intrinsic unpredictability and errors in determining the initial conditions.

As we were in an operational context, we used the output model to issue a daily weather bulletin reporting relevant meteorological phenomena and a daily alert bulletin containing a forecast of weather phenomena and expected ground effects for hydrogeological and hydraulic risks over 11 alert areas. Although the results were not completely satisfactory, the final output is an alert bulletin where the most critical areas have been individuated properly. We can assess that important progresses have been made in the meteorological modelling and in the operational chain of the Piedmont regional warning system.

Acknowledgements The authors would like to thank Gianpaolo Balsamo and his colleagues at ECMWF for the preparation of the ERA5 reforecast data and Prof. Enrico Ferrero (University of Eastern Piedmont) for the organization of the meeting "Alluvione 1994: il punto sulla situazione in Piemonte a 25 anni dalla tragedia". The event was partially financed by RISK-GEST Project-PITEM RISK, Interreg 2014-2020 Alcotra IT-FR. Furthermore, the authors would like to express gratitude to their colleagues in Arpa Piemonte for their sustenance, in particular to Chiara De Luigi, Fabio Antonini, and Elena Oberto. The simulations were performed in the framework of the ECMWF Special Project "Very high-resolution simulations of past flood events with COSMO model and ERA5". Eventually, a special thank goes to the National Department of Civil Protection for encouraging this kind of activities.

\section{Compliance with ethical standards}

Conflict of interest The authors declare that they have no conflict of interest.

Open Access This article is licensed under a Creative Commons Attribution 4.0 International License, which permits use, sharing, adaptation, distribution and reproduction in any medium or format, as long as you give appropriate credit to the original author(s) and the source, provide a link to the Creative Commons licence, and indicate if changes were made. The images or other third party material in this article are included in the article's Creative Commons licence, unless indicated otherwise in a credit line to the material. If material is not included in the article's Creative Commons licence and your intended use is not permitted by statutory regulation or exceeds the permitted use, you will need to obtain permission directly from the copyright holder. To view a copy of this licence, visit http://creativecommons.org/licenses/by/4.0/.

\section{References}

Arpa Piemonte (1998) L'evento alluvionale del 2-6 Novembre 1994 http://www.arpa.piemonte.it/ approfondimenti/temi-ambientali/geologia-e-dissesto/pubblicazioni/immagini-e-files/ev9496/ EventialluvionaliinPiemonte1994cap1.pdf

Bartholmes J, Todini E (2005) Coupling meteorological and hydrological models for flood forecasting. Hydrol Earth Syst Sci 9:333-346 
Bechtold P, Bazile E, Guichard F, Mascart P, Richard E (2001) A mass-flux convection scheme for regional and global models. Q J R Meteorol Soc 127:869-886

Binder P, Rossa A (1995) The Piedmont flood: operational prediction by the Swiss model. MAP Newsletter 2: $12-16$

Binder P et al (1996) MAP-Mesoscale Alpine Programme design proposal. MAP Programme Office, $77 \mathrm{pp}$. http://iacweb.ethz.ch/doc/publications/1996_BinderSchar_MAP_DP.pdf

Bonavita M, Torrisi L, Marcucci F (2010) Ensemble data assimilation with the CNMCA regional forecasting system. Q J R Meteorol Soc 136:132-145

Brath A (1995) Hydrometeorological aspects of the 1994 flooding in the Upper Po River Basin: frequency characteristics and real time predictability. U.S.-Italy Research Workshop on the Hydrometeorology, Impacts, and Management of Extreme Floods https:/www.engr.colostate.edu/ce/facultystaff/salas/us-italy/ index.html

Buzzi A, Tartaglione N (1995) Meteorological modelling aspects of the Piedmont 1994 flood. MAP Newsletter $3: 27-28$

Buzzi A, Tartaglione N, Cacciamani C, Paccagnella T, Patruno P (1995) Preliminary meteorological analysis of the Piedmont flood of November 1994. MAP Newsletter 2:2-6

Buzzi A, Tartaglione N, Malguzzi P (1998) Numerical simulations of the 1994 Piedmont flood: role of orography and moist processes. Mon Weather Rev 126:2369-2383

Buzzi A, Davolio S, Malguzzi P, Drofa O, Mastrangelo D (2014) Heavy rainfall episodes over Liguria in autumn 2011: numerical forecasting experiments. Nat Hazards Earth Syst Sci 14:1325-1340

Cassardo C, Loglisci N, Gandini D, Qian MW, Niu G-Y, Ramieri P, Pelosini R, Longhetto A (2002) The flood of November 1994 in Piedmont, Italy: a quantitative analysis and simulation. Hydrol Process 16:1275-1299

Castelli F (1995) Atmosphere modeling and hydrologic prediction uncertainty. U.S.-Italy Research Workshop on the Hydrometeorology, Impacts, and Management of Extreme Floods. https://www.engr.colostate.edu/ce/ facultystaff/salas/us-italy/index.html

Davies HC (1976) A lateral boundary formulation for multi-level pre-diction models. Q J R Meteorol Soc 102: $405-418$

Doms G, Baldauf M (2013) A description of the non-hydrostatic regional COSMO-model. Part III: Data Assimilation, 100 pp. DOI: https://doi.org/10.5676/DWD_pub/nwv/cosmo-doc_5.00_III. http://www. cosmo-model.org/content/model/documentation/core/cosmo_assimilation_5.00.pdf

Doms G, Baldauf M (2018) A description of the non-hydrostatic regional COSMO-model. Part I: Dynamics and numerics, 166 pp. https://doi.org/10.5676/DWD_pub/nwv/cosmo-doc_5.00_I. http://www.cosmo-model. org/content/model/documentation/core/cosmoDyncsNumcs.pdf

Doms $\mathrm{G}$ et al (2013) A description of the non-hydrostatic regional COSMO-model. Part II: Physical Parameterizations. 162 pp. https://doi.org/10.5676/DWD_pub/nwv/cosmo-doc_5.00_II. http://www. cosmo-model.org/content/model/documentation/core/cosmo_physics_5.00.pdf

Doswell CA III, Ramis C, Romero R, Alonso S (1998) A diagnostic study of three heavy precipitation episodes in the Western Mediterranean region. Weather Forecast 13:102-124

DPCM (2004) http://www.protezionecivile.gov.it/documents/20182/0/direttiva_pcm_27_02_2004.pdf/ de0e5428-f30e-474e-94a9-2c2eb8f203cf (in Italian)

Ferraris L, Rudari R, Siccardi F (2002) The uncertainty in the prediction of flash floods in the northern Mediterranean environment. J Hydrometeorol 3:714-727

Ferrero E, Balsamo G (2020) The 1994 Piedmont flood revisited. ECMWF newsletter 162. Winter 2020:8-9

Ferretti R, Low-Nam S, Rotunno R (2000) Numerical simulations of the Piedmont flood of 4-6 November 1994. Tellus A 52:162-180

Grazzini F, Fragkoulidis G, Pavan V, Antolini G (2020) The 1994 Piedmont flood: an archetype of extreme precipitation events in northern Italy. Bull Atmos Sci Technol. https://doi.org/10.1007/s42865-020-00018-1

Hersbach H, Bell B, Berrisford P, Hirahara S, Horanyi A, Muñoz-Sabater J, Nicolas J, Peubey C, Radu R, Schepers D, Simmons A, Soci C, Abdalla S, Abellan X, Balsamo G, Bechtold P, Biavati G, Bidlot J, Bonavita M, Chiara G, Dahlgren P, Dee D, Diamantakis M, Dragani R, Flemming J, Forbes R, Fuentes M, Geer A, Haimberger L, Healy S, Hogan RJ, Holm E, Janiskova M, Keeley S, Laloyaux P, Lopez P, Lupu C, Radnoti G, Rosnay P, Rozum I, Vamborg F, Villaume S, Thepaut J (2020) The ERA5 global reanalysis. Q J R Meteorol Soc 146:1999-2049

Khain P, Levi Y, Muskatel H, Shtivelman A, Vadislavsky E, Stav N (2021) Effect of shallow convection parametrization on cloud resolving NWP forecasts over the eastern Mediterranean. Atmos Res 247:105213

La Barbera P, Lanza L (1995) Hydrometeorological and remote sensing analyses: the case of recent extreme floods in Northern Italy, U.S.-Italy Research Workshop on the Hydrometeorology, Impacts, and Management of Extreme Floods https:/www.engr.colostate.edu/ce/facultystaff/salas/us-italy/index.html 
Marchi E, Roth G, Siccardi F (1995) The November 1994 flood event on the Po River: structural and nonstructural measures against inundations, U.S.-Italy Research Workshop on the Hydrometeorology, Impacts, and Management of Extreme Floods https://www.engr.colostate.edu/ce/facultystaff/salas/us-italy/index.html

Marsigli C, Montani A, Nerozzi F, Paccagnella T, Tibaldi S, Molteni F, Buizza R (2001) A strategy for highresolution ensemble prediction. II: limited-area experiments in four Alpine flood events. Q J R Meteorol Soc 127:2095-2115

Mellor GL, Yamada T (1982) Development of a turbulence closure model for geophysical fluid problems. Rev Geophys 20:851-875

Milelli M, Llasat MC, Ducrocq V (2006) The cases of June 2000, November 2002 and September 2002 as examples of Mediterranean floods. Nat Hazards Earth Syst Sci 6:271-284

Reinhardt T, Seifert A (2006) A three-category ice scheme for LMK. COSMO Newslett 6:115-120

Ritter B, Geleyn J (1992) A comprehensive radiation scheme for numerical weather prediction models with potential applications in climate simulations. Mon Weather Rev 120:303-325

Rotunno R, Ferretti R (2001) Mechanisms of intense Alpine rainfall. J Atmos Sci 58:1732-1749

Schraff C, Reich H, Rhodin A, Schomburg A, Stephan K, Periáñez A, Potthast R (2016) Kilometre-scale ensemble data assimilation for the COSMO model (KENDA). Q J R Meteorol Soc 142:1453-1472

Taylor KE (2001) Summarizing multiple aspects of model performance in a single diagram. J Geophys Res 106: $7183-7192$

Tiedtke M (1989) A comprehensive mass flux scheme for cumulus parameterization in large-scale models. Mon Weather Rev 117:1779-1800

Wicker L, Skamarock W (2002) Time-splitting methods for elastic models using forward time schemes. Mon Weather Rev 130:2088-2097 